\title{
Chambacú: entre atavismos y rizomas. Rastros de identidad en el corral de negros
}

\author{
Marcela Lora Díaz ${ }^{1}$ \\ Universidad Central de Venezuela
}

\section{Resumen}

Conceptos como los del melting pot, crisol, sincretismo, pluralidad, caos, y en los últimos años, la "poética de la relación", de Edouard Glissant, han sido utilizados para explicar y definir la constitución cultural y la identidad del ser Caribe. Glissant desarrolla la teoría de una identidad de raíz única que deviene en comunidades culturalmente atávicas e identidades rizomáticas producto de "la relación". El Caribe sería un espacio de identidades rizomáticas. En ese sentido, la li-teratura como expresión y manifestación de los imaginarios colectivos será permeada por estas problemáticas de la identidad. Teniendo en cuenta las teorías de "la relación" expuestas por Glissant, en el siguiente texto se rastrearán los tipos de identidades presentes en la novela Chambacú Corral de Negros, del escritor caribeño Manuel Zapata Olivella, la manera como los

\section{Abstract}

Concepts like those of the melting pot, hearth, syncretism, plurality, chaos, and in the last years Eduard Glissant's "the relationship poetry" have been used to explain and to define the cultural constitution and the being's Caribbean identity. Glissant develops the theory of an identity of unique root that becomes in culturally atavic communities and rhizomic identities, product of "the relationship." The Caribbean would be a space of rhizomic identities. In that sense, the literature as expression and performance of the imaginary communities will be influenced by these identity inquiries. Identity types present in the novel Chambacú Corral de Negros by the Caribbean writer, Manuel Zapata Olivella will be raked on the light of the theories of "the relationship" exposed by Glissant; the way the characters enter in "relationship" defining themselves as ata-

\footnotetext{
${ }^{1}$ Egresada del Programa de Lingüística y Literatura de la Universidad de Cartagena. Candidata a Magíster en Literatura Comparada (Universidad Central de Venezuela). Línea de investigación: Literatura del Caribe Hispano y Francófono.
} 
personajes entran en "relación" definiéndose como comunidades atávicas o rizomáticas y el resultado de dicha relación.

Palabras clave: rizoma, identidad rizomática, identidad de raíz única, poética de la relación, diversidad, totalidad-mundo. vic or rhizomic communities and the result of this relationship.

Keywords: rhizome, rhizomic identity, identity of unique root, relationship poetry, diversity, entirety-world.

"Debemos acostumbrarnos a la idea que nuestra identidad cambie al entrar en contacto con el otro".

Edouard Glissant.

"Se ha generado un proceso, común a todas las naciones del área (Caribe) de indagación de las fuentes culturales, de rescate del papel protagónico que en la historia del Caribe han tenido las razas y culturas oprimidas del Caribe para concluir con la aceptación de que las sociedades caribeñas, a pesar de las barreras lingüísticas, políticas y sociales, presentan un denominador común a todas ellas: el pluralismo cultural".

Lulú Giménez.

\section{Caribe: ¿multiplicidad diversificada, pluralidad, melting pot, rizoma o caos?}

"Se ha dicho muchas veces que el Caribe es la unión de lo diverso y tal vez sea cierto", manifiesta Benítez Rojo (1998: iii), a propósito de la relectura que hace del Caribe en su obra La isla que se repite, y es precisamente en esa diversidad que se buscan rastros de identidad del ser caribe. Para los estudiosos del Caribe, definir conceptos como identidad y cultura en este territorio resulta una ardua tarea, pues el hombre caribeño no se identifica, plenamente, con los elementos primarios de su formación: africano, europeo y amerindio. De igual manera, la pluralidad lingüística, étnica, religiosa y social no permiten estudiar el tema de la identidad como un bloque monolítico, sino como esencias diversificadas y autónomas que se encuentran y relacionan. 
Sin embargo, la problemática de la identidad en el Caribe ha sufrido transformaciones de acuerdo con los cambios socio-históricos vividos en la región. Así, durante algún tiempo, la identidad estuvo relacionada con lo racial y lo afrocaribeño ${ }^{2}$. Luego, con la tendencia artística barroca como manifestación de la fractalidad cultural. Lo realmente cierto es que el Caribe es zona de encuentro de diversas corrientes de la cultura universal, y en medio de la multiplicidad, lo racial, el mestizaje, la creolidad, el pensamiento de la errancia, la emigración, el exilio, el rastro y el "de tour" son elementos de confluencia de lo que podríamos denominar el "ethos caribeño".

Partiendo de la idea de una diversidad cultural en la cuenca caribeña (que dominará cualquier intento de definición de identidad) algunos caribeñólogos hablan de una identidad sincrética basada en una relación hegemónica y homogénea; otros plantean la pérdida de una identidad original en la "alteridad" (melting pot, crisol), y finalmente, en los últimos años, estudiosos apuestan a una identidad basada en la relación sin hegemonización ni homogeneización.

En el marco de esta concepción hallamos las bases del pensamiento y proyecto expuestos por el escritor martiniqueño Edouard Glissant. Para éste, cultura e identidad son conceptos interrelacionados: la identidad se define con base en la concepción de culturas atávicas y culturas compuestas que devienen de comunidades atávicas y comunidades compuestas respectivamente.

En ese sentido, las comunidades atávicas se fundamentan en la idea de una génesis preexistente a través de mitos fundacionales que crean filiaciones y legitimación a un territorio ${ }^{3}$. Estas comunidades generan una identidad de raíz única. Por su parte, las comunidades producto de la criollización, del encuentro y la relación, son conocidas como comunidades compuestas. Aquí los mitos fundacionales son reemplazados por relatos de elusión. Es el caso, según Glissant, de las comunidades del Caribe, que manifiestan una identidad rizomática, aunque en el proceso de criollización algunos de sus elementos culturales hayan sido subvalorados (tal es el caso del elemento negro). Afirma el escritor martiniqueño:

\footnotetext{
${ }^{2}$ Aunque como afirma Margarita Mateo Palmer y Luís Álvarez Álvarez en su libro El caribe en su discurso literario, lo étnico también se manifiesta en una identidad amerindia y hasta comprometida con lo hindú (léase coolitud).

${ }^{3}$ La filiación y la legitimación a un territorio justifican los procesos de expansión colonial, pues a la comunidad le es concedido un territorio que por filiación tiene derecho a acrecentar en sus límites.
} 
La noción de identidad de raíz única, que no siempre ha sido una noción letal y que ha producido obras espléndidas en la historia de la Humanidad, está relacionada con la sustancia misma de lo que he dado en llamar cultura atávica. [...] He relacionado el principio de una identidad rizoma con la existencia de culturas compuestas, es decir, de culturas en las que se practica una criollización. (Glissant, 2002b: 32).

Para Glissant, las concepciones de una identidad de raíz única e identidad rizomática pueden explicar, en primera instancia, fenómenos culturales del Caribe (tras la idea de la constitución de este territorio como una comunidad compuesta); no obstante, más allá de explicaciones culturales, la idea de rizoma y la relación constituyen un modelo de pensamiento, un imaginario de la diferencia, aplicable a cualquier región del mundo4: "En mi opinión, sólo una poética de la relación, es decir, un imaginario, nos permitirá comprender estas fases y esta interdependencia de situaciones de los distintos pueblos, en la actualidad, en el mundo" (26).

Por otra parte, la literatura como forma de expresión y manifestación de los imaginarios culturales de un colectivo se ve permeada por toda esta problemática de la identidad en tanto búsqueda de una (¿varias?) esencia (s) y autorreflexión por parte del escritor. Es en ese campo donde pueden develarse con mayor asiduidad las diversas identidades que se construyen, reconstruyen y deconstruyen.

Así encontramos escritores de todo el Caribe (anglófono, hispano, francófono, continental e insular) construyendo a través de la dialogía y los personajes distintas identidades (homogeneizadoras, totalizantes, transparentes, absolutas, rizomáticas). En el Caribe colombiano son varios los escritores que indagan el asunto desde distintas ópticas: Gabriel García Márquez, Germán Espinosa, Ramón Illián Bacca y Manuel Zapata Olivella, quien en su novela Chambacú corral de negros nos plantea la cuestión del encuentro entre dos culturas. En ese orden de ideas, pretendo develar los tipos de identidades presentes en la novela de Zapata Olivella, tomando como base teórica las conceptualizaciones de Edouard Glissant.

\footnotetext{
" Precisamente los conceptos de "identidad rizomática" e "identidad de raíz única" Glissant los toma de una teoría del pensamiento de Deleuze y Gauttari, en su libro Mil mesetas, para aplicarlo al ámbito cultural, y de allí al imaginario colectivo (pensamiento de la relación).
} 


\section{Lo uno y no lo diverso}

“Los hombres bajarán hasta la calle enfangada, entrarán muy despacio y comprometerán sus cuerpos con la obra acometida. El viento del mediodía ha cubierto los techos, las mujeres alzan ante sus ojos destello puro, los perros vanazas hacia el mar (en donde está el claro festín de los estercoleros y de los reproches). Mirad, el mar me ha deportado hacia la fértil jornada, oh desde tan lejos voy avanzando con la marea hacia esta ausencia y este rostro. Y si quieren conservar ese gusto por estas tierras intrincadas que tiene mi palabra, no he perdido mi tiempo ni he consumido, en vano, la hojarasca de este corazón".

Edouard Glissant, Sal negra.

Chambacú, para finales del siglo XIX y principios del XX, era un islote habitado por más de quince mil familias, que se asentaron allí tras ser expulsadas del centro amurallado de Cartagena de Indias. Este terreno pantanoso e insalubre, ubicado frente a las fortificaciones del lago El Cabrero, se constituirá en el espacio ficcional donde se desarrollarán las vivencias, conflictos, encuentros y desencuentros de los personajes de la novela de Manuel Zapata Olivella. Los primeros habitantes de Chambacú, descendientes de esclavos traídos de África, constituyen una comunidad compuesta, producto de la criollización entre el elemento europeo, africano y amerindio. Lo anterior se hace evidente en algunas marcas del mestizaje y sincretismo expuestas en el discurso narrativo de lo racial y lo religioso.

El primer signo se manifiesta en la figura de la Virgen de la Candelaria como parte del imaginario católico, también concebida en los rituales de santería como la diosa de los umbrales y mujer de Changó. Aunado a lo anterior, nos encontramos con una Virgen hecha de palo y ennegrecida (reafirmando lo sincrético). Lo racial se evidencia a través del ojos del otro, concretizado en la mirada de Inge, para quien "entre los mulatos de Chambacú le resultaba evidente el mestizaje" (el destacado es mío) (Zapata Olivella, 1990: 87).

No obstante, desde el espacio hasta el imaginario colectivo de los habitantes de Chambacú, encontramos marcas de una propensión hacia lo atávico. Chambacú es una isla (aislada) y sus habitantes rechazan el contacto con lo otro. Para Edouard Glissant, las culturas compuestas tienden a lo atávico, en la medida que aspiran a una perdurabilidad temporal que "sólo le otorgaría una identidad de raíz única" (2002: 63). En este desplazamiento se mueve la comunidad de Chambacú (la cual he tomado, en primera instancia, por razones 
históricas y de formación como una comunidad compuesta): desde lo compuesto hacia lo atávico. Esto lo podemos rastrear en varios elementos como lo espacial, lo racial, los mitos fundacionales de legitimación y filiación y los vestigios del inconsciente en algunos personajes.

Uno de los conflictos desarrollados en la novela está relacionado con la intención de las autoridades de Cartagena de Indias de desplazar a los mulatos habitantes de Chambacú. Entonces, a lo largo de la novela, hallaremos razones por las cuales los habitantes de la isla deben permanecer allí. Y uno de los discursos más reiterados evoca la fundación y los primeros habitantes de la misma que ratifican una legitimidad y una filiación. Así lo expresa el narrador de la novela, focalizado en el personaje de la señorita Domicilia:

La maestra escuchaba otras voces. Las de sus padres que reclamaban la defensa de su casa. Extraños querían destruirla. Miró el retrato del padre. La cabeza rala, cubierta de ensortijadas vedijas, negro el rostro. Su madre, en otra fotografía, tenía la misma sangre. Gente de ahí, nacida con el calor del carbón que quemaron. Ella era hija de los primeros fundadores [...] Combatiría. Sus padres la verían luchar por lo que les pertenecía. (Zapata Olivella, 1990: 115).

Con relación al imaginario colectivo podemos dilucidar, por medio de los comentarios y actitudes de los habitantes de Chambacú tras la llegada de Inge, la propensión hacia lo atávico, y por ende, hacia una identidad de raíz única. De allí la preocupación de la Cotena por la entrada de Inge al árbol genealógico de su descendencia africana; no tanto por lo racial, sino por los valores culturales del otro (una forma de rechazar la relación). En ese orden de ideas, lo otro se concibe como inmoral, impuro, frágil, una presencia extraña que incomoda. En voz de la Cotena:

\begin{abstract}
¿Una gringa? Recapitulo. ¿Qué humos se han metido en la cabeza de ese imbécil para traer una gringa a Chambacú? ¿Será una puta? ¡Dios sabe en qué burdel la recogió!

-Virgen Santa, perdóname que tenga malos pensamientos ante ti, pero prefiero que me sepulten a verme emparentada con una vagabunda por culpa de mi hijo. (40).
\end{abstract}

Otras voces del pueblo: “-¡Miren ustedes, estropearme mis puercos por no tirar al agua a esa puta!" (41); "-Yo oí decir a Constantino que en cuanto se descuide José Raquel, venderá el estanquillo y con un poco de plata que le muestre a la gringa se irá a vivir con él en barrio 
decente" (70); “-¡Igual de loca que él! Los dolores de cabeza que nos traerá esa mujer. Ahora sí comprendo porqué dicen que la guerra es la peste" (45).

Adicionalmente, el elemento racial negro se erige como un signo primordial de identidad para los habitantes de la isla. Por eso, todo aquello que primeramente fuese de color distinto en Chambacú se ennegrece conservando el peso de lo atávico. Ejemplo de lo anterior lo encontramos en la imagen de la Virgen ennegrecida. Así cualquier relación con lo otro (lo blanco) será repudiada. Es lo que ocurre con Dominguito, quien fuese hijo de un blanco: "Dominguito le creció en el vientre como una maldición. El pelo rojo y la piel lechosa. Ajeno a la isla" (18).

Asegura Glissant que la problemática de la propensión a lo atávico desde las comunidades compuestas, en el Caribe, "se encarna en una especie de vestigio inconsciente" (2002: 60). Una suerte de nostalgia hacia una existencia única. En Chambacú, la tendencia a lo atávico no sólo está presente en el imaginario y el modus vivendi de la comunidad, sino que hallamos un personaje que reproduce un pensamiento de raíz única ${ }^{5}$. Más allá de la legitimación por medio de los mitos fundacionales, en Máximo la tendencia atávica se presenta como un vestigio inconsciente y una nostalgia hacia un lugar dejado atrás: la vieja África.

Este personaje manifiesta su identidad de raíz única en el rechazo hacia Inge. Empero, más que un rechazo a lo otro, podemos vislumbrar el temor a la "contaminación" con la civilización por su superioridad $^{6}$. Una superioridad, manifiesta en Inge, que no está vinculada con la tecnología, sino con la capacidad que tiene el otro de relacionarse, de poder establecer la relación:

El ojo de Inge. Creía que a ella debía en gran parte su desazón. Hubiera querido estar metido en su pupila. Mirar su propio mundo desde ese ángulo europeo. Las costumbres rústicas. La lucha por salir de la barbarie. La mente cargada de supersticiones. Esa noche larga y tenebrosa de cuatrocientos años. La vieja África transportada en los hombros de sus antepasados. [...] Lo desnudaba con sus ojos azules, con su

\footnotetext{
${ }^{5}$ Máximo, hijo de la Cotena, quien lucha por mantener la legitimidad territorial en Chambacú, es el personaje que más teme a la relación con el otro.

${ }^{6}$ En ese orden de ideas encontramos un segundo nivel de análisis: no sólo la relación raíz única y rizoma sino la relación Próspero-Caliban (civilización y barbarie). El rechazo de Caliban a Próspero por representar otros valores.
} 
olfato, con su palabra. Frente a ella hasta sentía que la piel se le arrugaba para cerrarle el paso a su mirada exploradora. [...] Esa aparente inexistencia era lo que más le mortificaba. Quería ocupar un lugar entre ellos, por muy estrecho que fuera. [...] Si al menos hubiera opuesto su pasividad. El grito. El rechazo. 0 el silencio desdeñoso. Callaba. Cedía. Se plegaba porque se sabía más fuerte. Superioridad de comprensión. De entender y analizar. (79-80).

Máximo, por vestigios de un remanente atávico, siente una suerte de nostalgia, pero no desarraigo hacia el lugar impuesto. Es más evidente la pretensión de mantener sus vínculos con África, obviando otros elementos de la criollización, los cuales corroboran su propensión a lo absoluto, que una idea de desarraigo o erancia:

No es ocasional que Chambacú, corral de negros, haya nacido al pie de las murallas. Nuestros antepasados fueron traídos aquí para construirlas. Los barcos negreros llegaban atestados de esclavos provenientes de toda África. Mandingas, Yolofos, Minas, Carabalíes, Fiafara, Yorubas, más de cuarenta tribus. (96).

Finalmente la presencia de Inge tendría que obligatoriamente propiciar el contacto, no necesariamente la relación. Máximo, la Cotena, Clotilde y todos los habitantes de Chambacú experimentarían la alteridad.

\section{La llegada de Inge: signos de la relación}

"Experimentar la totalidad-mundo desde el lugar de origen consiste en establecer una relación y no consagrarse a la exclusión".

Edouard Glissant.

Inge es una sueca que conoce a José Raquel (hermano de Máximo e hijo de la Cotena) en Europa, durante la guerra de Corea. Contraen matrimonio y se radican en Chambacú. Este personaje se constituirá en un referente para reafirmar la identidad de los chambaculeros y establecer el contacto con lo otro ${ }^{7}$. El proceso de establecimiento de una relación entre Inge y los habitantes de Chambacú está marcado, a lo largo de la segunda parte de la novela, por acontecimientos y

\footnotetext{
${ }^{7}$ Basada esta idea en la teoría de que sólo reafirmamos la identidad al entrar en contacto con la otredad.
} 
situaciones que, en primera instancia, se desarrollan dentro de la casa de la Cotena. El primer contacto de "la gringa" con un personaje de naturaleza atávica lo vivencia con la Cotena:" "Sin decir nada al hijo, sobaba la mano a Inge que hacía esfuerzos por desprenderse de ella" (Zapata Olivella, 1990:41). El proceso se desarrollará en tres etapas:

1. Un (re)conocimiento de lo otro, lo extraño.

2. Una aceptación de la otredad (metamorfosis).

3. La relación que determina el ser.

En el primer momento, vemos aún a Inge que no observa claramente los rostros de quienes la rodean. Acostada y encerrada en el toldo, inicia un reconocimiento a través de los olores y sonidos, los cuales intenta comparar con su mundo. Los habitantes de Chambacú, entonces, serán como sombras que no puede esclarecer:

El aire seco. Lo advirtió desde que el barco comenzó a surcar las aguas de Caribe. Algo de eso había leído sobre el trópico. El oleaje azul, bajo la desbordante luz, se le antojaban más cargado de sal que el mar Báltico. La piel pegajosa. No eran simples alteraciones atmosféricas, sino de su propio cuerpo. Al cruzar frente a las Martinicas, se intensificó su desasosiego [...] Chambacú. El llanto reprimido. ¡Ah! ¡Si hubiese podido desatarlo! Sol. Persistente taladro de luz trepanándola. El olor penetrante de arenque ahumado. Creyó que era el aliento de su propia sangre extravasada, viscosa, correteando por su piel. Sorprendida advirtió que ella misma tenía el olor que brotaba de los rincones y se cuajaba sobre las superficies de las aguas empantanadas. Su infancia. La pequeña aldea donde había nacido cerca la mar. [...] Después entró en una especie de sopor, de enajenación. No podía tomar conocimiento de nada. Apenas una vaga visión que se mezclaba a los olores obsesionantes. Los rostros de las personas distorsionadas como si los mirara a través de unos lentes borrosos. (Zapata Olivella, 1990: 42-43).

En el segundo momento, las sombras son esclarecidas e Inge sale de la cama para entrar en relación con los miembros de la familia de su esposo. En esta etapa el lenguaje es un elemento esencial para establecer la relación, pues: “Qué habría pasado si ella no hubiese

\footnotetext{
${ }^{8}$ Vale aclarar que Inge ya había entrado en contacto con el otro al conocer a José Raquel; sin embargo, debido a los viajes realizados durante la guerra, José Raquel poseía un imaginario y visión de mundo distinta a la de los demás habitantes de la isla.
} 
hablado castellano? Habrían permanecidos mudos, sin poder comunicarse" ( 51).

De igual manera, por medio de las vivencias, el personaje inicia una metamorfosis donde la relación con el otro no se da en igualdad de condiciones, ya que ella sentía superioridad cultural. Son los tambores los que contribuyen al embrujamiento: la metamorfosis. "Los tambores en la distancia. Más que resonar, la embrujaban, deseaba repeler su acción diabólica" (Zapata Olivella, 1990: 61).

Finalmente, la Relación como signo del contacto con el otro, sin superioridades, sin homogeneización, sin identidades cuestionadoras, ni pesos tiránicos, sino las raíces entrando en contacto con otras raíces. Inge sufrió la transformación: "Su rostro blanco, tiznado por la luz humeante de la lámpara" (Zapata Olivella, 1990: 80), puesto que "debemos acostumbrarnos a que nuestra identidad cambie al entrar en contacto con el otro." (Glissant, 2000: 2) Sin embargo, el cambio no entra en contradicción con la singularidad, la esencia:

Su parsimonia quitando a su ropa el hollín o el excremento de los gallos. Las dos maletas que perfumaban el rancho aunque estuvieran cerradas, [...]. Limpiaba las paredes de cartón y tabla como si lustrara mármol. El instinto de su mano para remover todos los objetos y dejarlos en su mismo lugar. (Zapata Olivella, 1990: 80).

Y los tentáculos de la relación que Inge utilizaba, tocaron a Máximo y a todo Chambacú: lo atávico en relación con lo rizomático consagrado a la no exclusión.

Nos dice Glissant en Introducción a una poética de lo diverso: "no necesito comprender al otro, es decir, reducirlo al modelo de mi propia transparencia, para vivir con ese otro o construir algo con él" (2002b: 72). Y eso entendió Inge. No era comprensión de Próspero a Caliban, era sencillamente vivir y luchar juntos en la construcción de un futuro para Chambacú. Así lo asumió la población: la relación ya estaba dada y continuaría. Lo atávico había muerto y "la dobladora de tabaco podría cerrar los ojos a Máximo pues muchos ya los tenían abiertos.

-Yo me voy a hacer la permanente

-Tu pelo no lo estiran ni con almidón

-Si yo fuera rubia, como Inge, me lo mandaría a rizar" (Zapata Olivella: 121) 
Este es uno de los últimos diálogos de la novela. Un final abierto e imprevisible en el cual se revelan signos de la relación y el intercambio cultural.

\section{Bibliografía}

Álvarez Álvarez, Luis \& Mateo Palmer, Margarita. (2005). El caribe en su discurso literario. Santiago de Cuba: Editorial Oriente.

Benítez Rojo, Antonio. (1998). La isla que se repite. Honover: Ediciones del Norte.

Deleuze, Pilles \& Guattari, Félix. (1991). Mil mesetas : Pretextos.

Giménez, Lulú. (1991). Caribe y América latina. Caracas: Monte Ávila.

Glissant, Edouard. (2002). El discurso antillano. Caracas: Monte Ávila. Trad.: Aura Marina Boadas y Amelia Hernández. .(2002b). Introducción a una poética de lo diverso. Barcelona: Ediciones del Bronce. Trad.: Luis Cayo Pérez Bueno. .(2002c). Fastos y otros poemas Cuba: CASA (Fondo Editorial Casa de Las Américas). Trad.: Nancy Morejón. (Enero, 2000). Declaración recogida por Tirthankar Chanda en http//www.diplomatie.gouv. fr. / label. France. No. 38.

Zapata Olivella, Manuel. (1990). Chambacú corral de negros. Bogotá: Altamir. 
